\title{
Saponin Bitterness Reduction of Carica papaya Leaf Extracts through Adsorption of Weakly Basic Ion Exchange Resins
}

\author{
Sharifah Nuruljannah Syed Amran, Noraziani Zainal Abidin, Haslaniza Hashim (D), \\ and Saiful Irwan Zubairi ii
}

Centre for Biotechnology and Functional Food, Faculty of Science and Technology, Universiti Kebangsaan Malaysia (UKM), 43600 Bangi, Selangor, Malaysia

Correspondence should be addressed to Saiful Irwan Zubairi; saiful-z@ukm.edu.my

Received 2 March 2018; Accepted 14 August 2018; Published 24 September 2018

Academic Editor: Efstathios Giaouris

Copyright ( 2018 Sharifah Nuruljannah Syed Amran et al. This is an open access article distributed under the Creative Commons Attribution License, which permits unrestricted use, distribution, and reproduction in any medium, provided the original work is properly cited.

\begin{abstract}
Carica papaya that belongs to Caricaceae family has long been known as a traditional medicine for dengue fever, as well as for anticancer and antiinflammatory studies following identification of beneficial phytochemicals such as saponins in the leaves. Unfortunately, the compound has been known to induce a bitter taste in the leaf extract for human consumption, making them unpopular and nonconsumer friendly. Thus, this study aims to observe the potential adsorption of saponin compound from $C$. papaya leaves using ion exchange resins as an adsorbent for the reduction of bitter-taste-inducing saponins. This study uses three types of weakly basic ion exchanging resins, namely, Amberlite IRA-67, Diaion WA30, and Diaion WA21J, at different adsorbent doses of $5 \%(\mathrm{w} / \mathrm{v})$ and $10 \%(\mathrm{w} / \mathrm{v})$. The Peleg model suggests that the extraction of saponins from C. papaya leaves lasted for 12.50 hours yield a maximum amount of saponins, $9.31 \mathrm{mg} / \mathrm{g}$. Further study shows that there is a significant difference $(p<0.05)$ of saponin adsorption percentage between these three types of resins. The Diaion WA30 resin showed the highest percentage of adsorption at $87.83 \%(\mathrm{w} / \mathrm{w})$ as compared to the other two $5 \%(\mathrm{w} / \mathrm{v})$ loaded resin. The $10 \%(\mathrm{w} / \mathrm{v})$ resin-loaded Diaion WA30 demonstrated the highest overall adsorption capacity as much as $97.59 \%(\mathrm{w} / \mathrm{w})$ with the shortest exhaustive time of 4.99 hours. The overall acceptance of samples in sensory evaluation treated with ion exchange resins gave good response in which the sample treated with $10 \%(\mathrm{w} / \mathrm{v})$ resin-loaded Diaion WA30 demonstrated the highest overall acceptance in parallel with having the lowest bitterness score as compared to other samples and fresh samples (untreated). The Langmuir constant $\left(R_{\mathrm{L}}\right)$ was less than one (0.167-0.398), indicating the adsorption of saponins onto Diaion WA30 was favourable.
\end{abstract}

\section{Introduction}

C. papaya, locally known as papaya pear or pawpaw, originates from the Caricaceae family that stems into six other genera including those of Carica, Jarilla, Horovitzia, Jacaraita, Vasconcellea, and Cylicomorphia $[1,2]$. The plant has been used as traditional medicine to treat various diseases that affect human health. In Nigeria alone, it has been reported that the plant is widely used as a cure by the general population of those residing in selected local government areas of Kwara State including Moro, Ifelodun, Ekiti, Afon, and Offa for ailments such as typhoid, malaria, jaundice, diarrhea, measles, and yellow fever [3]. Meanwhile, its widespread uses in the Asia region are more likely to be associated with treatment for dengue fever. An array of studies have been reported on the use of $C$. papaya plant, particularly the leaves in the treatment of dengue fever that contribute to an increased thrombocytes count in rats from $948.0 \times 10^{3}$ to $1198.5 \times 10^{3}$ after 72 hours of observation following the administration of papaya leaf extracts, as well as a significant difference $(p<0.05)$ in hematocrit levels between the control group and the experimental group who were given capsules made from papaya leaf extracts over the course of $6-9$ days $[4,5]$. There has also been a report on increased level of platelet count from $55 \times 10^{3} \mu \mathrm{l}^{-1}$ to $168 \times 10^{3} \mu^{-1}$, increased white blood cell (WBC) count from $3.7 \times 10^{3} \mu \mathrm{l}^{-1}$ to 
$7.7 \times 10^{3} \mu \mathrm{l}^{-1}$, as well as increased count of neutrophils from $46.0 \%$ to $78.3 \%$ over the course of 5 days in dengue patients following administration of papaya leaf extracts [6].

The ability of the leaves to be used as a cure for these diseases is most likely due to the presence of bioactive compounds and multiple phytochemicals in the leaves. In 2007, at least seven different bioactive compounds in the leaves of the $C$. papaya plant were identified including flavanols, $t$, tannins, alkaloids, and carpaine [7, 8]. In fact, the highest phytochemicals in C. papaya leaves were also saponins, which make up to $0.022 \pm 0.10 \%$ of all the phytochemicals tested present in the same part [5]. Although it bears the potential as a cure or medicine for many ailments, commercially available medicinal products from C. papaya leaf extracts have hindered its potential due to its bitterness, greatly believed to be caused by saponins, greatly believed to be caused by saponins $[9,10]$. Previous research has found that one of the challenges of using traditional herbs as medicine for human health is the bitter taste associated with it particularly those that contain saponins [11]. Recently, many researchers have remarked that saponins from a variety of plants including soybeans are very much responsible for the bitter taste of the extract even in low concentrations [12]. It was found that there was indeed a positive correlation between the soya saponin concentration in pea plant extracts $(0.1 \%-0.3 \% \mathrm{w} / \mathrm{w})$ and its bitterness level analysed via sensory evaluation. [13]. This was also true for saponins that generally cause bitter tastes in dry pea samples [14].

In conjunction to this problem, numerous attempts have been made to remove saponins, to prevent resurfacing of bitter taste in traditional medicinal herbs. As highlighted over the years, many methods have been developed for the extraction, isolation, and quantification of saponin compound [15]. These methods are usually separated into two classes of conventional extraction technique and green extraction techniques with the later emphasizing more on being environment friendly [16]. However, conventional extraction techniques are still being preferred by 70 to $30 \%$ due to foregoing the cost of heavy-equipment required for the extraction or isolation process. Conventional methods for the extraction of saponins are usually maceration (soaking) and the Soxhlet method in reflux; meanwhile, the extraction techniques involving green technology are those of ultrasoundassisted extraction techniques and microwave-assisted extraction techniques [17]. This method manages to block activation of the saponin compound through the addition of phytosterols, but this method is said to have harmful effects when performed on animal feed as it will cause stunted animal growth and eventually death [18].

As such, the objective of this research was to assess the effectiveness of the saponin adsorption process of $C$. papaya leaf extracts using three different types of weakly basic ion exchange resins to propose a new possible way of removing saponins, other than to determine the content, percentage of adsorption, and exhaustive time of the overall adsorption process as well as measuring the level of sensory acceptance of C. papaya leaf extracts which has undergone the adsorption process.

\section{Methodology}

2.1. Materials and Chemicals. Mature C. papaya leaves (of unspecified variety) were obtained from Banting, Selangor area in Malaysia. Three weakly basic ion exchanger resins (Amberlite IRA-67, Diaion WA30, and Diaion WA21J) were purchased from Sigma-Aldrich (St. Louis, MO, USA), and their specifications are described in Table 1. The organic solvent, methanol of $99 \%$ (v/v) analytical purity grade, was purchased from Bendosen. Other analytical reagents and chemicals including vanillin, sulphuric acid, hydrochloric acid, acetic acid, and ethanol were also purchased from Bendosen. Escin of $95 \%$ (w/w) purity used as a standard was obtained from Sigma-Aldrich (St. Louis, MO, USA).

2.2. Experimental Design. A simple $3 \times 2$ factorial design was employed to determine the saponin adsorption capacity (\%) of two adsorbent doses/load based on the previous study with respect to three types of ion exchange resins, as shown in Table 2.

2.3. Sample Preparation. C. papaya leaves were obtained from the consistent source in Banting. Only the matured, dark green leaves without any damage were chosen for this study. Prior to processing, all mature C. papaya leaves were stored at $-20^{\circ} \mathrm{C}$ to minimize the deterioration of any bioactive compounds present. The leaves were then cut into small pieces and freeze-dried. C. papaya leaves were then grounded by using Kenwood grinder before sieved to $\leq 1 \mathrm{~mm}$ particle size using a $1 \mathrm{~mm}$ stainless steel mesh sieve. Briefly, ground leaves were extracted in water under optimal conditions identified using Response Surface Methodology (RSM) at $85^{\circ} \mathrm{C}$ and a water-to-leaf ratio of $20: 1 \mathrm{ml} / \mathrm{g}$. The extracted solution was filtered and then stored at $-18^{\circ} \mathrm{C}$ for the next adsorption studies [19]. Figure 1 shows the process undertaken for the preparation of saponin-enriched water extracts from C. papaya leaves.

2.4. Peleg Model. The Peleg mathematical model was used to estimate the optimum value for saponin adsorption as well as the exhaustive time of the overall adsorption process. The graph obtained from this model is able to describe the characteristics of the sorption process well [20]. In addition, the Peleg mathematical model is very advantageous to sorption studies involving limited preliminary data [21, 22]. The Peleg mathematical equation is shown as

$$
M_{t}=M_{0} \pm \frac{t}{\left(k_{1}+k_{2} t\right)} \text {, }
$$

where $M_{t}$ is the concentration of saponins at time, $t(\%), M_{0}$ is the initial concentration of saponins (\%), $t$ is time in hour basis $(\mathrm{h})$, and $k_{1}$ and $k_{2}$ describe the Peleg rate $\left(\mathrm{h} \%^{-1}\right)$ and the Peleg capacity constant $\left(\%^{-1}\right)$, respectively. It should also be noted that a " \pm " value is possible wherein a positive " + " value describes the process of adsorption or absorption and 
TABLE 1: Specification of each ion weakly basic anion exchange resin chosen for the adsorption of saponin from C. papaya leaves.

\begin{tabular}{lccc}
\hline Product specifications & & Ion exchange resins & \\
& Amberlite IRA-67 & Diaion WA21J & Diaion WA30 \\
\hline Resin type & Weakly basic anion & Weakly basic anion & Weakly basic anion \\
Matrix & Acrylic gel & Divinyl benzene-styrene & Divinyl benzene-styrene \\
Functional group & Polyamine & Polyamine & Tertiary amine \\
Ionic form & Free base & Free base & Free base \\
Ion exchange capacity $(\mathrm{meq} / \mathrm{ml})$ & 1.6 & 2.0 & 1.5 \\
Moisture content $(\%)$ & $56-64$ & $40-52$ & $63-55$ \\
Min particle size $(\mu \mathrm{m})$ & 610 & 650 & 680 \\
Density & 1.80 & 1.07 & 1.05 \\
Max operational temperature $\left({ }^{\circ} \mathrm{C}\right)$ & 60 & 100 & 100 \\
Operational pH & $7-9$ & $0-9$ & $0-9$ \\
Regeneration chemical & Sodium hydroxide & Sodium hydroxide & Sodium hydroxide \\
\hline
\end{tabular}

TABLE 2: Experimental design of saponin adsorption by three different types of ion exchange resins.

\begin{tabular}{lcc}
\hline Adsorbent dose/load \% (w/v) & Types of weakly basic ion exchange resins \\
\hline 5 & Diaion WA21J & Amberlite IRA-67
\end{tabular}

The influence of dose adsorbent and type of resin on adsorption capacity (\%) was assessed.

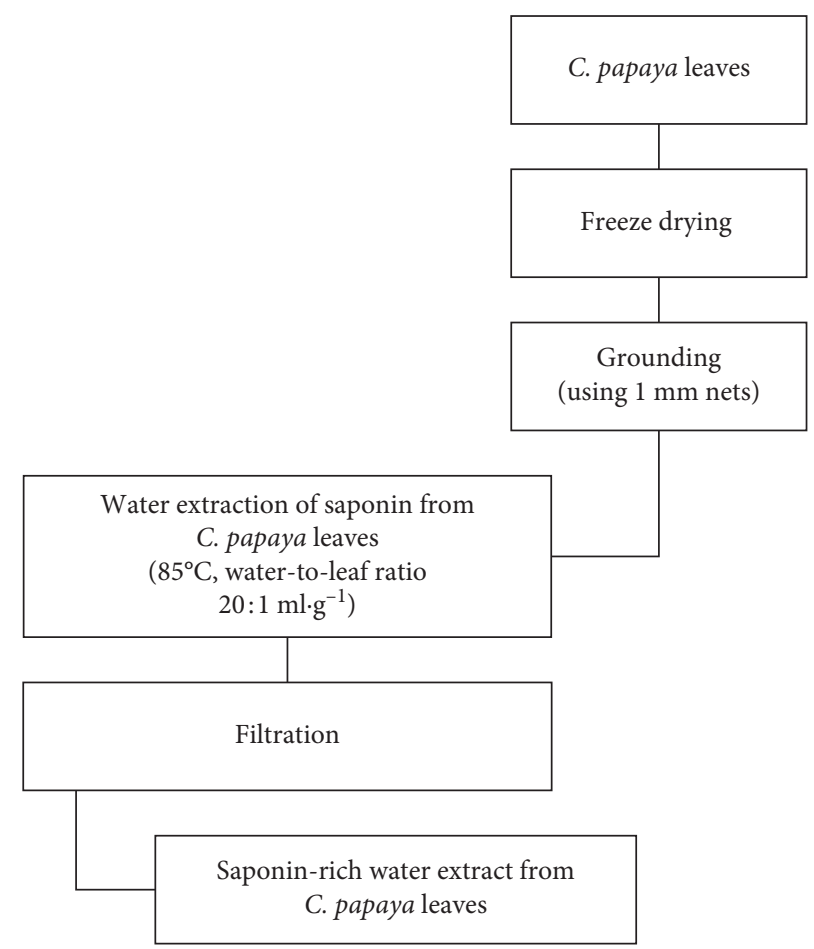

Figure 1: Preparation of saponin-enriched water extracts from C. papaya leaves.

a negative “-” value describes the desorption and drying process $[22,23]$. The values for $k_{1}$ and $k_{2}$ are calculated based on the equation of the linear graph of time/concentration of saponins ( $\mathrm{min} / \mathrm{mg}$ ) vs. time ( $\mathrm{min})$, where $k_{1}$ is equal to the $y$ intercept of the graph and $k_{2}$ is equal to the slope $[24,25]$.
Rate of adsorption $=\frac{1}{k_{1}}(\mathrm{mg} / \mathrm{min})$,

Maximum concentration of extract $=\frac{1}{k_{2}}(\mathrm{mg})$. 
TAвLE 3: Specifications and conditions of saponin detection in $C$. papaya leaves extract using high-performance liquid chromatography.

\begin{tabular}{lc}
\hline Specifications & Conditions \\
\hline Column & Chromolith performance RP-18e \\
Detector & UV-VIS \\
Wavelength & $210 \mathrm{~nm}$ \\
Temperature & $23 \pm 1^{\circ} \mathrm{C}$ \\
Mobile phase (pump A) & Deionized water $+0.1 \%(\mathrm{v} / \mathrm{v})$ acetic acid \\
Mobile phase (pump B) & Methanol $(\mathrm{HPLC}$ grade) \\
Flow rate & $1.0 \mathrm{ml} / \mathrm{min}$ \\
Elution mode & Binary gradient \\
Injection volume & $20 \mu \mathrm{l}$ \\
\hline
\end{tabular}

TABLE 4: Solvent gradient conditions of the high-performance liquid chromatography for saponin quantification.

\begin{tabular}{lccc}
\hline Time $(\mathrm{min})$ & Pump A & Pump B & Flow rate $(\mathrm{ml} / \mathrm{min})$ \\
\hline 0 & 29.6 & 70.4 & 1.0 \\
15 & 40 & 60 & 1.0 \\
30 & 40 & 60 & 1.0 \\
31 & 0 (stop) & 0 (stop) & - \\
\hline
\end{tabular}

2.5. Adsorption Studies of Saponins Using Weakly Basic Ion Exchange Resins. The 5\% (w/v) and 10\% (w/v) of each weakly type basic ion exchange resins were conditioned as proposed by the manufacturer and then placed into a conical flask before being mixed directly with C. papaya leaf extracts rich in saponins [26]. The mixture was placed in an environmental shaker at a rotation of 120 per minute, and the temperature was set to $25{ }^{\circ} \mathrm{C}$ [27]. The mixture was left until optimum adsorption was achieved; reading of saponin content was taken at every two hour interval in between the process. The adsorption capacity, $S(\%)$, was later calculated as

$$
S=\frac{C_{0}-C}{C_{0}} \times 100,
$$

where $C_{0}$ and $C$ are the initial concentration of saponin and the final concentration of saponin, respectively.

\subsection{Determination of Saponin Content Using Spectrophoto-} metric Methods (UV Spectrophotometer). Determination of the saponin content of $C$. papaya leaf extracts throughout the process was done based on the method used by Vuong et al. [28]. Approximately $0.5 \mathrm{ml}$ extracts were mixed with $0.5 \mathrm{ml}$ of $8 \%(\mathrm{w} / \mathrm{v})$ vanillin and $5 \mathrm{ml}$ of $72 \%(\mathrm{v} / \mathrm{v})$ of sulphuric acid, cooled on ice for $5 \mathrm{mins}$ and then incubated at $60^{\circ} \mathrm{C}$ for $15 \mathrm{~min}$. The mixture was then cooled on ice in room temperature before being measured at $560 \mathrm{~nm}$ using a UV spectrophotometer. Escin was used as the standard for the calibration curve, with results expressed as $\mathrm{mg}$ of escin equivalents per $\mathrm{g}$ of sample (mg ASE $\mathrm{g}^{-1}$ ).

\subsection{Quantification of Saponin Compound Using High-} Performance Liquid Chromatography. Determination and quantification of saponins using chromatographic technique in this study was carried out to make a comparison of the presence compounds in each treated and untreated sample.

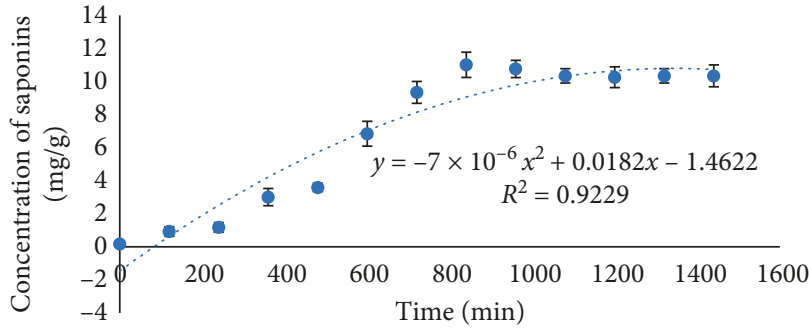

FIGURE 2: Kinetic equilibrium profile of saponin concentration $(\mathrm{mg} / \mathrm{g})$ with respect to extraction time $(\mathrm{min})$.

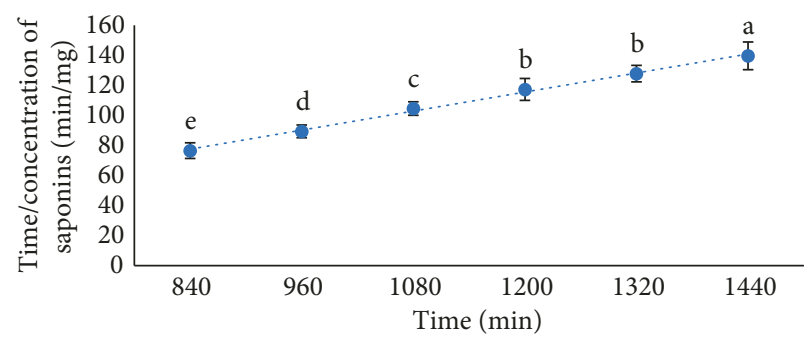

FIGURE 3: Linear relationship between time/concentration of saponins ( $\mathrm{min} / \mathrm{mg}$ ) with respect to extraction time (min). a-e: different alphabets indicate a significant difference $(p<0.05)$.

The condition and method proposed for the chromatography were based on few references with slight modification as described in Table $3[29,30]$. Table 4 describes the solvent gradient conditions of the HPLC used.

2.8. CIE $L^{*} a^{*} b^{*}$ Color Test. Color measurement $\left(L^{*}, a^{*}, a^{*}\right)$ was carried on the surface of the samples using a Minolta Chromameter (CR 400, Japan). Reading the analysis is later on described using the CIE $L^{*}$ (lightness), $a^{*}$ (redness), and $a^{*}$ (yellowness) system. The device was calibrated using a provided white tile before measuring a colored sample.

2.9. Sensory Evaluation. A descriptive test was carried out to assess acceptance of four attributes associated with the objective of the research, mainly the aroma, color, taste (bitterness), and overall acceptance of the samples before and after treatment. A total of 10 semi-trained panels were selected to undergo the sensory evaluation. Each panel evaluates eight type of samples consisting of six treated samples that has undergone the adsorption process, one untreated sample (fresh sample), and one reference sample (RUJ) on a numerical scale with a seven-point grading. Minitab software $\left(17^{\text {th }}\right.$ Version) was used for data analysis to determine the standard deviation and mean as well as to produce ANOVA test results that determine significant differences between the samples tested. The significant difference is based on a $95 \%$ confidence level $(p<0.05)$.

\section{Results and Discussions}

3.1. Exhaustive Saponin Extraction. The kinetic graph in Figures 2 and 3 was obtained after the adsorption process was left to set for 1440 minutes (24-hours). Previous study 


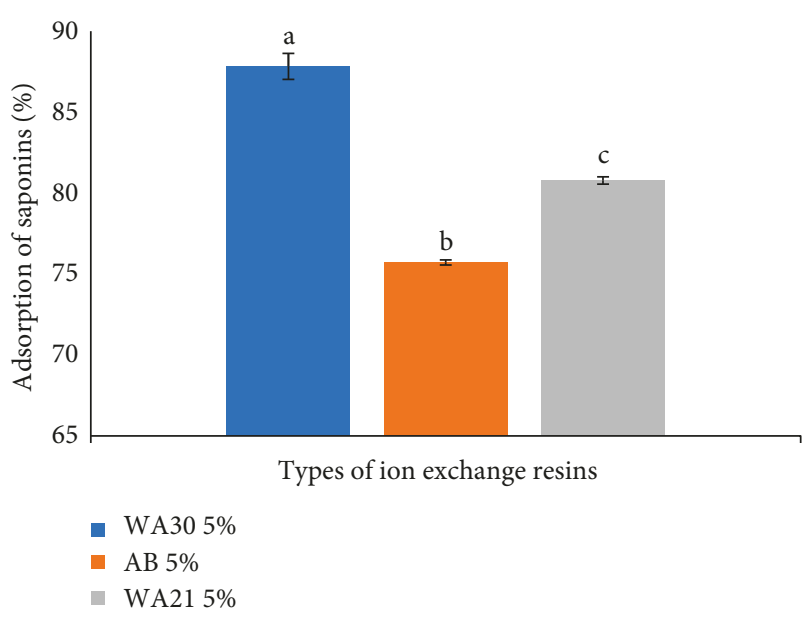

Figure 4: Percentage of saponins adsorbed (\%) by three different weakly basic ion exchange resins at $5 \%(\mathrm{w} / \mathrm{v})$ adsorbent dose. a-c: different alphabets indicate a significant difference $(p<0.05)$.

has shown that the complete saponin extraction should not be more than 41 hours as the extract was more likely to degrade rapidly which is indicated by the change of color and smell [31].

For determining the exhaustive time and maximum amount of extract, the Peleg model was carried out based on the time/yield $(\mathrm{min} / \mathrm{mg}$ ) versus the time interval (min) graph. Figure 3 shows the linear relationship of the time/total saponin content $(\mathrm{min} / \mathrm{mg})$ against time $(\mathrm{min})$ in order to determine the $K_{1}$ and $K_{2}$ coefficients for the value of extraction rate and the maximum amount of extract obtained. The coefficient of $K_{1}$ value is obtained from the $y$ intercept value, whereas the $K_{2}$ coefficient value is the gradient value through the time linear $(t) /$ concentration versus time $(t)$ graph. Based on the equation above, the average rate of saponin extraction were calculated to be $0.05 \pm 0.001 \mathrm{mg} / \mathrm{min}$ for approximately $12.50 \pm 1.08$ hours with a total yield of $9.31 \pm 1.26 \mathrm{mg} / \mathrm{g}$. The extraction was repeated $(n=3)$, and the exhaustive extract concentration was obtained approximately with the predicted value.

\subsection{Saponin Adsorption Capacity Using Weakly Basic Ion} Exchange Resin. Adsorption studies of saponins using weakly basic ion exchanger has previously been carried out elsewhere using Amberlite IRA-67 at two known adsorbent doses of 0.1 g and $0.5 \mathrm{~g}$. However, it was discovered that the particular resin showed potential to be able to effectively adsorb saponins up to $80 \%(\mathrm{w} / \mathrm{w})$ of the compound from the total concentration [32]. Generally, it is noted that resins with a microporous structure are able to adsorb organic compounds rather well [33]. Figure 4 shows the amount of saponins adsorbed (\%) by three different weakly basic ion exchange resins at the adsorbent preconditioned dose of $5 \%(\mathrm{w} / \mathrm{v})$.

Figure 4 suggests that there was a significant difference $(p<0.05)$ between all three-ion exchange resins used at 5\% $(\mathrm{w} / \mathrm{v})$ adsorbent dose, in which the highest adsorption was from samples treated with the resin Diaion WA30. This was marked by a few factors including the mean size of resin

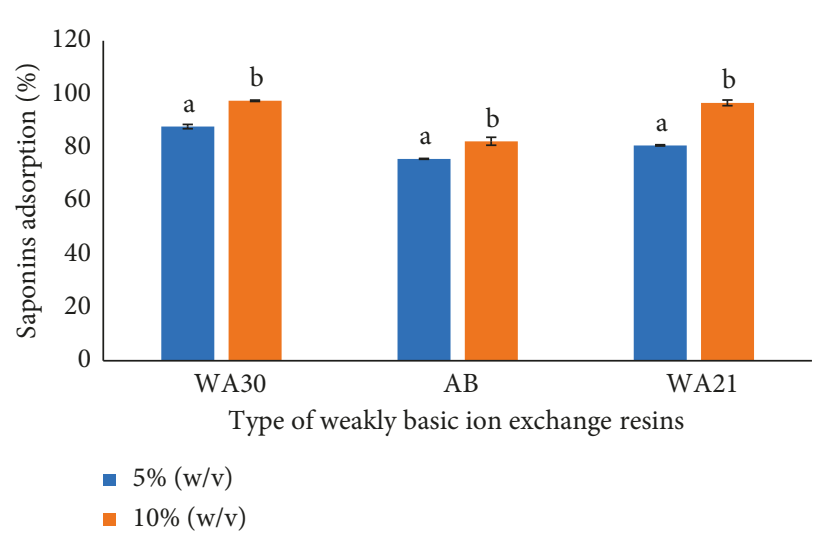

Figure 5: Effect of adsorbent dose at 5\% (w/v) and 10\% (w/v) on the saponin adsorption (\%) of three different types of weakly basic ion exchange resins. a, b: different alphabets indicate a significant difference $(p<0.05)$.

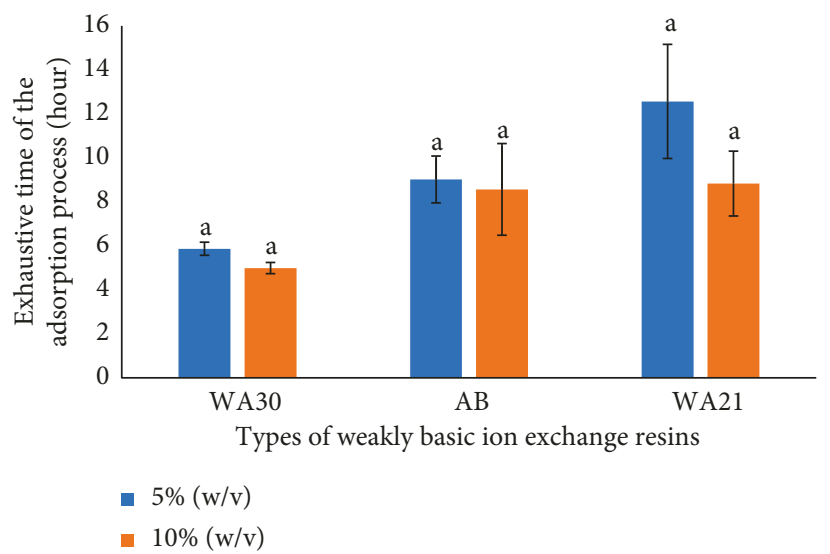

Figure 6: Effect of adsorbent dose at 5\% (w/v) and 10\% (w/v) on the saponin adsorption exhaustive time (hour). a: the same alphabet indicate no significant difference $(p>0.05)$.

particles $(\mu \mathrm{m})$ and the resin structure. Based on Table 1, it should be noted that Diaion WA30 recorded the largest mean for its particle size at $680 \mu \mathrm{m}$ in comparison with Diaion WA31J $(650 \mu \mathrm{m})$ and Amberlite IRA-67 $(610 \mu \mathrm{m})$. Previous study has shown that adsorption (\%) of lead ions $\left(\mathrm{Pb}^{2+}\right)$ and cadmium ions $\left(\mathrm{Cd}^{2+}\right)$ increased proportionately to the mean size of adsorbent particles from $106 \mu \mathrm{m}$ to $500 \mu \mathrm{m}$ [34]. The results proved that an increase in the particle size would mean an increase in micropores between the particles as well, thus effectively increasing the surface area for the overall adsorption process. On another note, the type of matrix of the resin would also come to affect the adsorption process. Based on Table 1, the Amberlite IRA-67 was the only resin with an acrylic gel-type of matrix unlike both Diaion resins which possess a DVB-styrene matrix structure. This could very well contribute to the effectiveness of the adsorption process that nongel DVB-styrene type matrixes has larger porosity that serves for the adsorption process of chromium ions $\left(\mathrm{Cr}^{2+}\right)$ [35].

Between two adsorbent doses of 5\% (w/v) and 10\% (w/v) used, it was found that each type of resin showed 
a significant difference $(p<0.05)$ on the adsorbed saponins, as shown in Figure 5. The adsorbent dose however did not produce any significant difference $(p>0.05)$ on the overall time of the adsorption process, as shown in Figure 6.

Previous study has shown that an increase in adsorbent dose would unconditionally increase the amount of adsorption by ion exchange resins [36-38]. This trend was indeed in line with the textile dyes $\left(\mathrm{Pb}^{2+}\right.$ and $\mathrm{Cd}^{2+}$ ions captures) bioadsorption waste treatment process and as it increased proportionally with respect to the adsorbent dose of $2.5 \mathrm{~g} / \mathrm{L}$ to $20.0 \mathrm{~g} / \mathrm{L}[39,40]$. This trend was subtly attributed to the increase in the surface area for the adsorption process as the dose increases. The exhaustive time of the overall adsorption process however was not affected by the adsorbent dose as the adsorption process generally would not be significantly different from each other no matter how much the dose were given after 2-3 hours of the process. This would be possibly due to achieving a state of quasi-equilibrium at the earliest recorded maximum adsorption time.

3.3. Quantification of Saponins. Figure 7 shows the standard curve produced by escin was used as an external standard for saponin quantification. Figure 8 shows the chromatogram profiles of saponin availability of each untreated and treated samples after the overall adsorption process.

As shown in Figure 8, the only visible peak obtained from the chromatogram was the fresh extract (untreated) at retention time of $26.78 \pm 1.04$ mins. Samples that were treated using ion exchange resin showed absolutely no apparent peaking around the expected retention time of 20 to $27 \mathrm{~min}$, most likely due to saponins being adsorbed at almost 75-95\% $(\mathrm{w} / \mathrm{w})$ from its total amount in detected prior to adsorption. The absence of a peak during the expected retention time therefore solidifies the fact that the adsorption process had occurred between the samples and the resin to remove the particular saponin compound.

3.4. CIE $L^{*} a^{*} b^{*}$ Color Test. Figure 9 shows the result of the CIE $L^{*} a^{*} b^{*}$ color test for both fresh (untreated) and treated samples after the adsorption process was concluded. Resin treatment was observed to have significant $(p<0.05)$ effect on the color intensity of the samples compared to the fresh (untreated) sample. It is noted that compared to the untreated sample with an $L^{*}$ value of $56.93 \pm 1.01$, samples that were treated particularly with Diaion WA30 10\% (w/v) showed the lightest color intensity of $80.94 \pm 0.72 L^{*}$ reading. This is in line with the findings of the panel sensory evaluation that concluded samples treated with this particular resin gave out an impression of being weak in color compared to the fresh sample. The same is also true for the $b^{*}$ reading that describes the intensity of yellowish color in the sample. Based on these findings, it is probable that sensory acceptance of the samples was affected by the color representation of the sample when served to the sensory panels $[34,35]$.

3.5. Sensory Evaluation. Figure 10 shows the result of the sensory evaluation responses, consisting of four tested attributes including color, aroma, taste (bitterness), and overall acceptance. Resin treatment was observed to have significant $(p<0.05)$ effect on all of the attributes tested compared to the fresh (untreated) sample. It was noted that for almost all of the attributes, samples treated with Diaion WA30 resin at an adsorbent dose of $10 \%(\mathrm{w} / \mathrm{v})$ managed the lowest scores (for aroma intensity, color intensity, and bitter taste), while managing to also top overall acceptance amongst the sensory panel compared to all other samples. Samples treated with the same resin at an adsorbent dose of 5\% (w/v) also threaded behind carefully; however, as Figure 5 ultimately described above, the difference of total saponin adsorbed might attribute to the slight difference between the two. It is noteworthy that in relation to the amount of saponin adsorbed throughout the process, the overall acceptance increased in order, as well as the bitterness of the sample from Amberlite IRA-67 $<$ Diaion WA21J $<$ Diaion WA30.

3.6. Adsorption Isotherm Modelling. Data have been plotted based on Langmuir adsorption isotherm in Figure 11. $C_{\mathrm{e}} / Q_{\mathrm{e}}$ gradient against $C_{\mathrm{e}}$ is aimed to obtain the Langmuir constant value $\left(R_{\mathrm{L}}\right)$. The Langmuir constant value $\left(R_{\mathrm{L}}\right)$ is used for the purpose of connecting isotherm of adsorption of pure components [36]. Another feature of the Langmuir equation can be translated into a nondimensional constant $\left(R_{\mathrm{L}}\right)$ equation. The calculated $R_{\mathrm{L}}$ value shown in Table 5 lies in the range 0 and 1 . Based on previous study [37], the $R_{\mathrm{L}}$ value determines the isotherm whether it is unfavourable $\left(R_{\mathrm{L}}>1\right)$, linear $\left(R_{\mathrm{L}}=1\right)$, favourable $\left(0<R_{\mathrm{L}}<1\right)$, and nonreversible $\left(R_{\mathrm{L}}=0\right)$. Based on the results in this study, the dimensionless separation factor $\left(R_{\mathrm{L}}\right)$ shows that the Resin Diaion WA30 with absorbent dose $10 \%(\mathrm{w} / \mathrm{v})$ can be used as an alternative to commercial adsorbent in bioactive removal in plants.

\section{Conclusion}

Based on the research conducted, it was found that the selected resins showed a great potential adsorbent for saponin adsorption extracted from C. papaya leaves. The study found that there were significant differences $(p<0.05)$ between three types of resins used against saponin adsorption (\%) in which Diaion WA30 showed the highest adsorption as compared to other resins. The differences were believed to be due to the mean particle size of the resins $(\mu \mathrm{m})$ and the resin matrix structure itself. In addition, the dry weight of the resin used showed significant differences $(p<0.05)$ on the adsorption process in which the resin load of $10 \%(\mathrm{w} / \mathrm{v})$ showed higher adsorption as compared to that of $5 \%(\mathrm{w} / \mathrm{v})$. This is most likely due to the increase in dry weight resin which subsequently increases the amount of resin beads or area for the efficient adsorption. However, the adsorbent dose/load did not literally affect the overall exhaustive exposure/incubation time $(p>0.05)$. Moreover, sensory evaluation suggests that samples treated with weakly basic ion exchange resins were in fact affected the aroma, color, taste (bitterness), and overall acceptability compared to the fresh (untreated) samples $(p<0.05)$. The overall acceptance of samples treated with ion exchange resins gave a considerable positive responses in reducing saponin bitterness in 


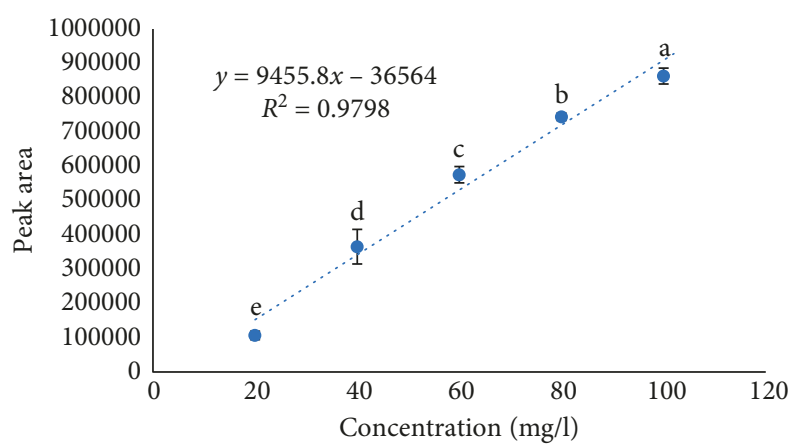

Figure 7: Escin standard curve at concentration $20 \mathrm{mg} / \mathrm{l}$ to $100 \mathrm{mg} / \mathrm{l}(n=3)$. a-e: different alphabets indicate a significant difference $(p<0.05)$.

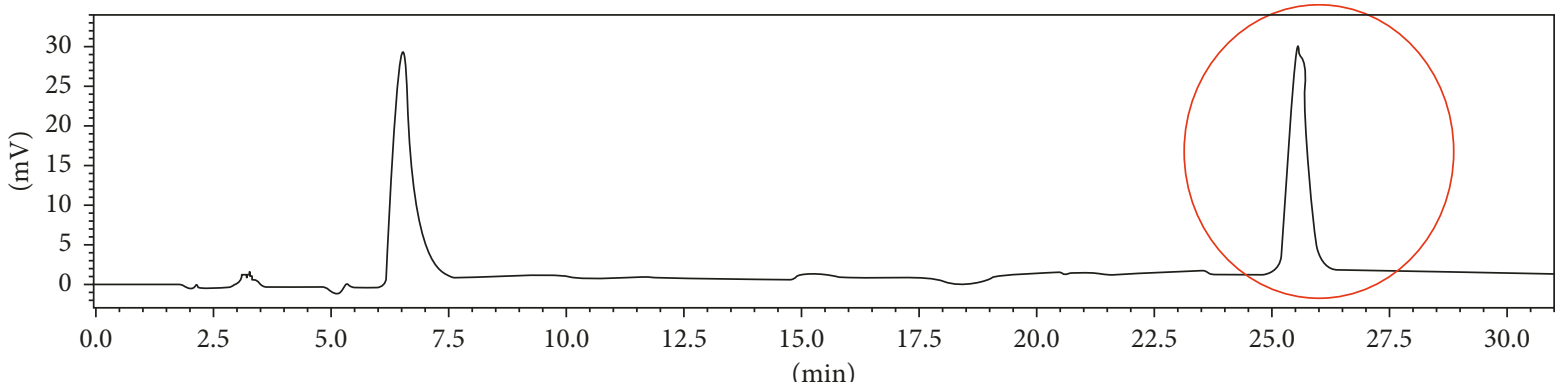

(a)

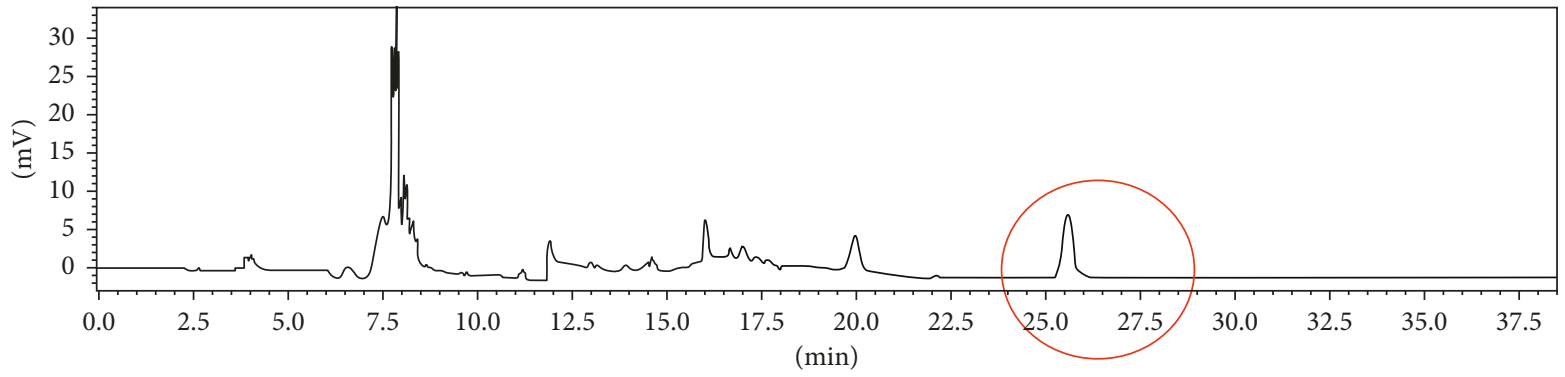

(b)

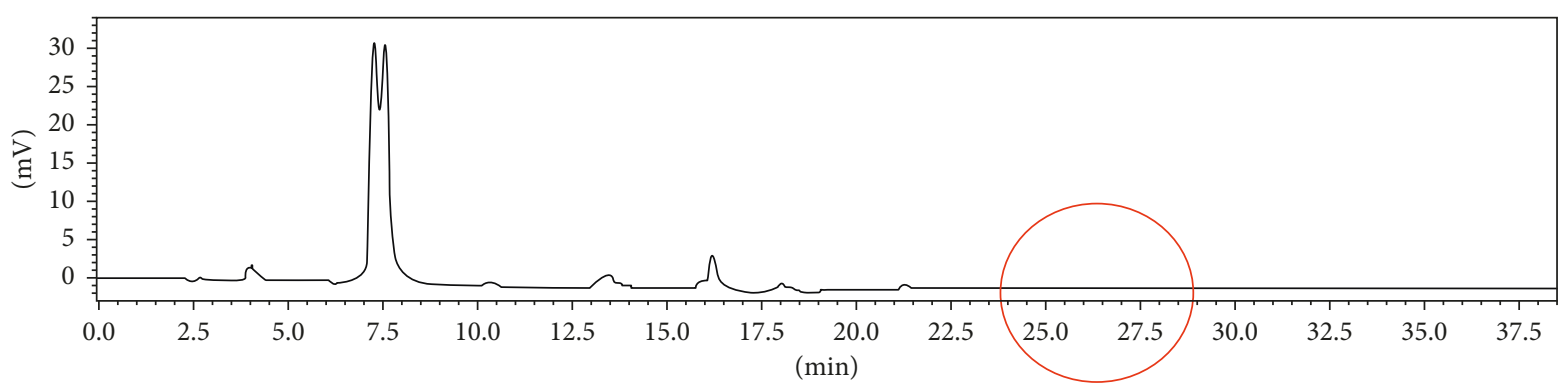

(c)

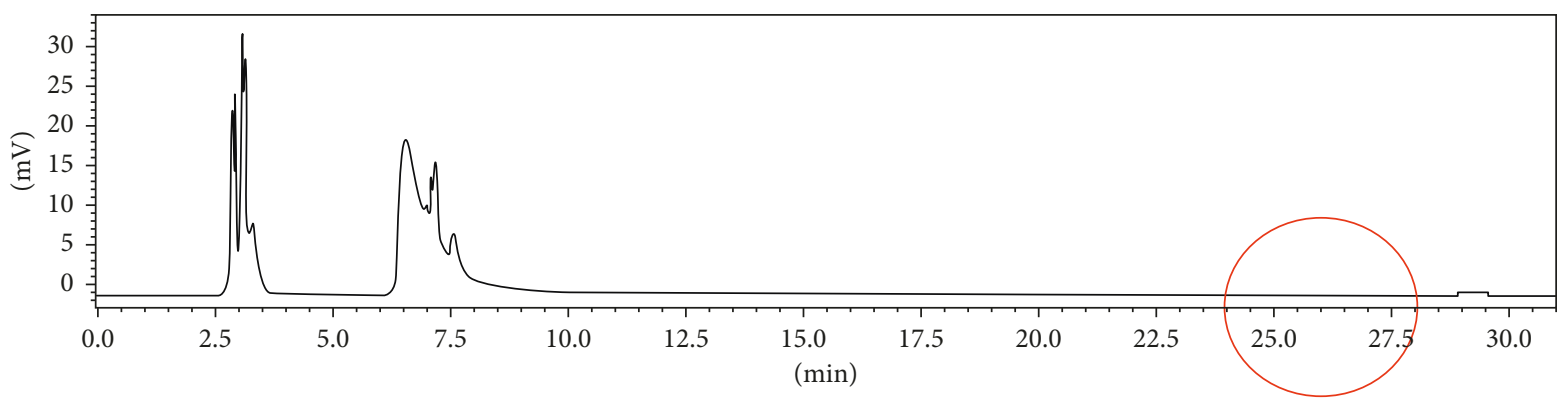

(d)

Figure 8: Continued. 


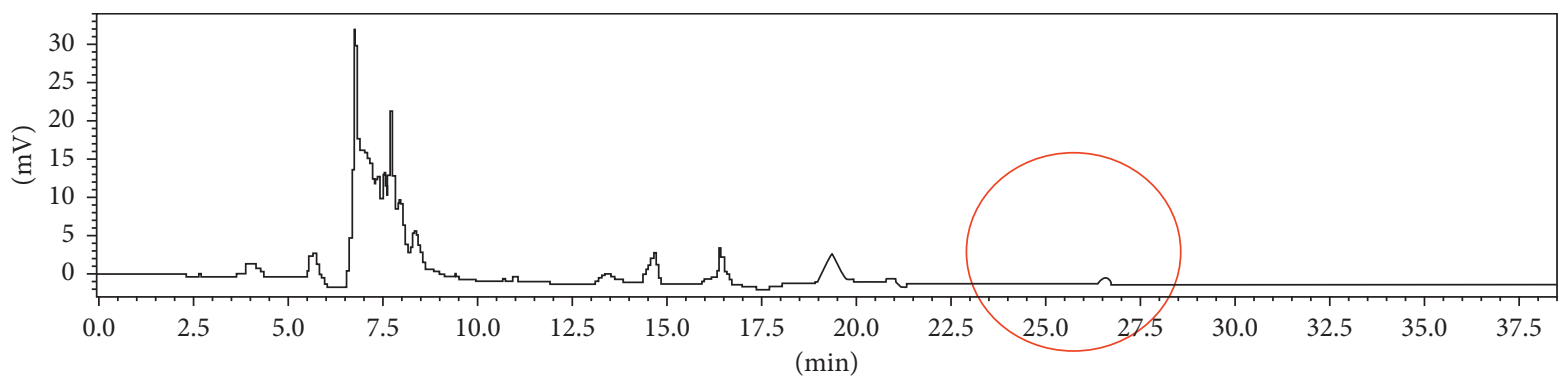

(e)

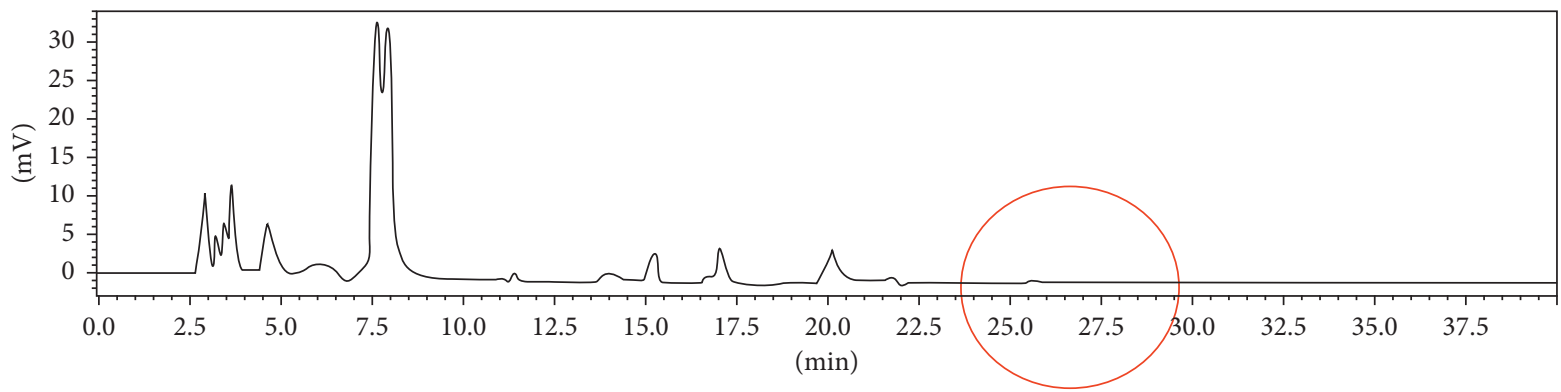

(f)

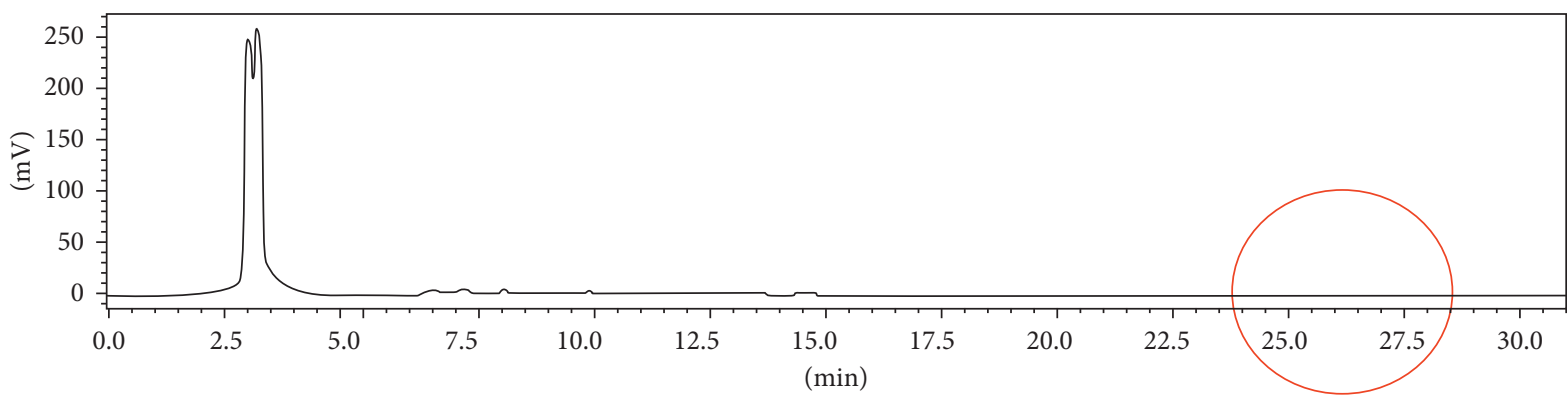

(g)

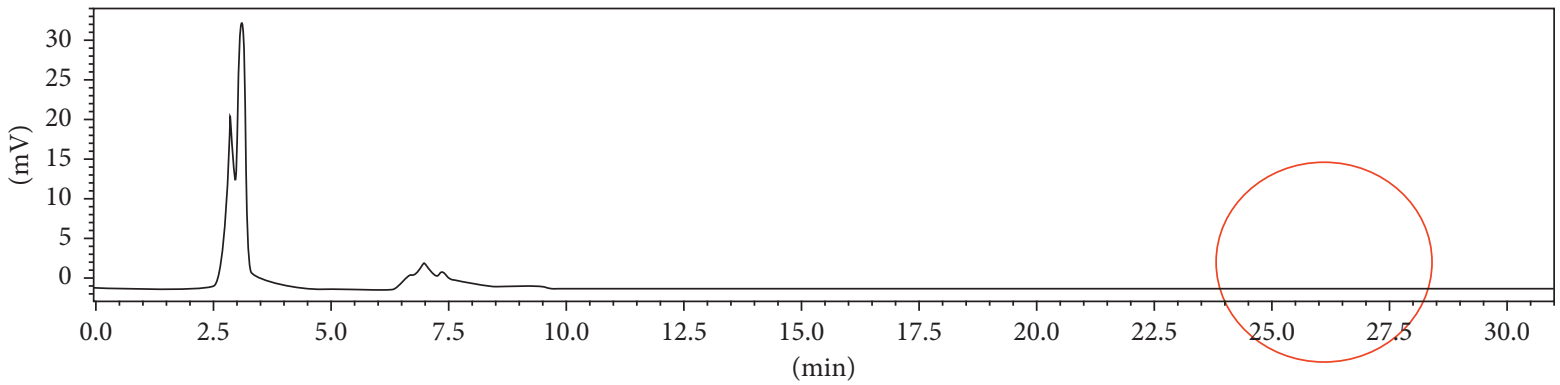

(h)

FiguRE 8: HPLC chromatogram profiles of C. papaya leaves extract (a) standard (escin); (b) fresh (untreated); (c-h) samples treated with ion exchange resins. Red circle in $(\mathrm{b}-\mathrm{h})$ shows the retention time of the saponin compound. (a) Peak of standard (control: escin) at concentration of $100 \mathrm{mg} / \mathrm{l}$ using $210 \mathrm{~nm}$ detection wavelength. (b) Peak of fresh sample (untreated) using $210 \mathrm{~nm}$ detection wavelength. (c) No peak detected at the expected retention time of samples treated with Diaion WA21 resin at 5\% (w/v) adsorbent dose using $210 \mathrm{~nm}$ detection wavelength. (d) No peak detected at the expected retention time of samples treated with Diaion WA21 resin at 10\% (w/v) adsorbent dose using $210 \mathrm{~nm}$ detection wavelength. (e) No peak detected at the expected retention time of samples treated with Amberlite IRA-67 resin at $5 \%(\mathrm{w} / \mathrm{v})$ adsorbent dose using $210 \mathrm{~nm}$ detection wavelength. (f) No peak detected at the expected retention time of samples treated with Amberlite IRA-67 resin at 10\% (w/v) adsorbent dose using $210 \mathrm{~nm}$ detection wavelength. (g) No peak detected at the expected retention time of samples treated with Diaion WA-30 resin at 5\% (w/v) adsorbent dose using $210 \mathrm{~nm}$ detection wavelength. (h) No peak detected at the expected retention time of samples treated with Diaion WA-30 resin at $10 \%(\mathrm{w} / \mathrm{v})$ adsorbent dose using $210 \mathrm{~nm}$ detection wavelength.

which the sample treated with $10 \%(\mathrm{w} / \mathrm{v})$ resin load Diaion WA30 recorded the highest overall acceptance in parallel with having the lowest bitterness score compared to other samples, including samples of fresh (without treatment). This result was also consistent with the earlier findings of the adsorption study that proved Diaion WA30 at an adsorbent 


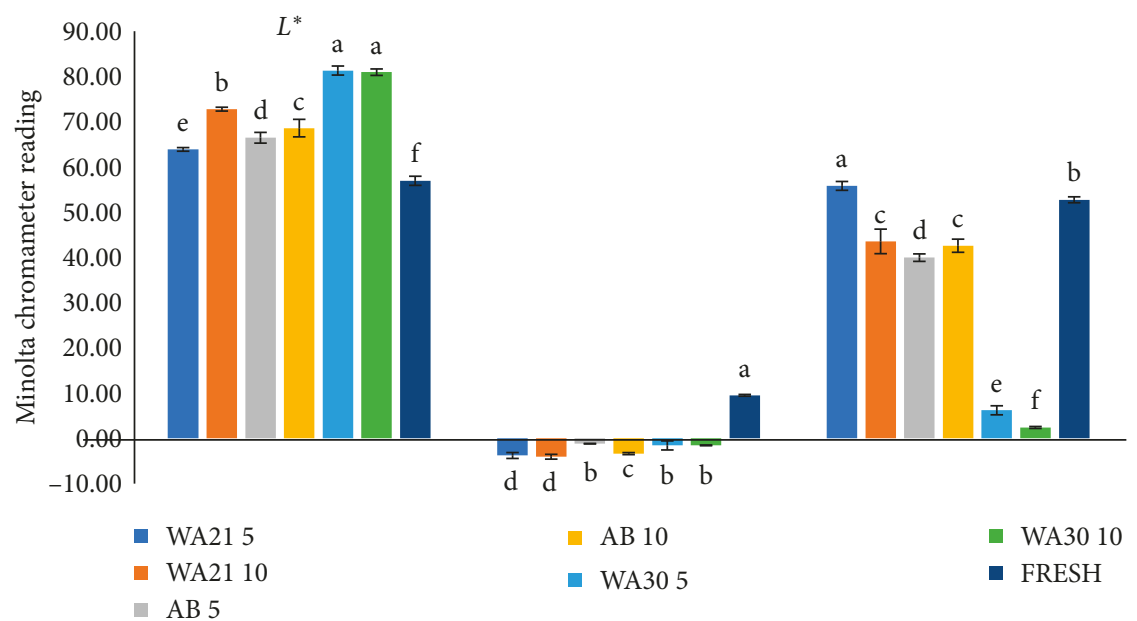

Figure 9: CIE $L^{*} a^{*} b^{*}$ reading by the Minolta Chromameter on fresh (untreated) and treated C. papaya leaf extracts. a-f: different alphabets indicate a significant difference $(p<0.05)$.

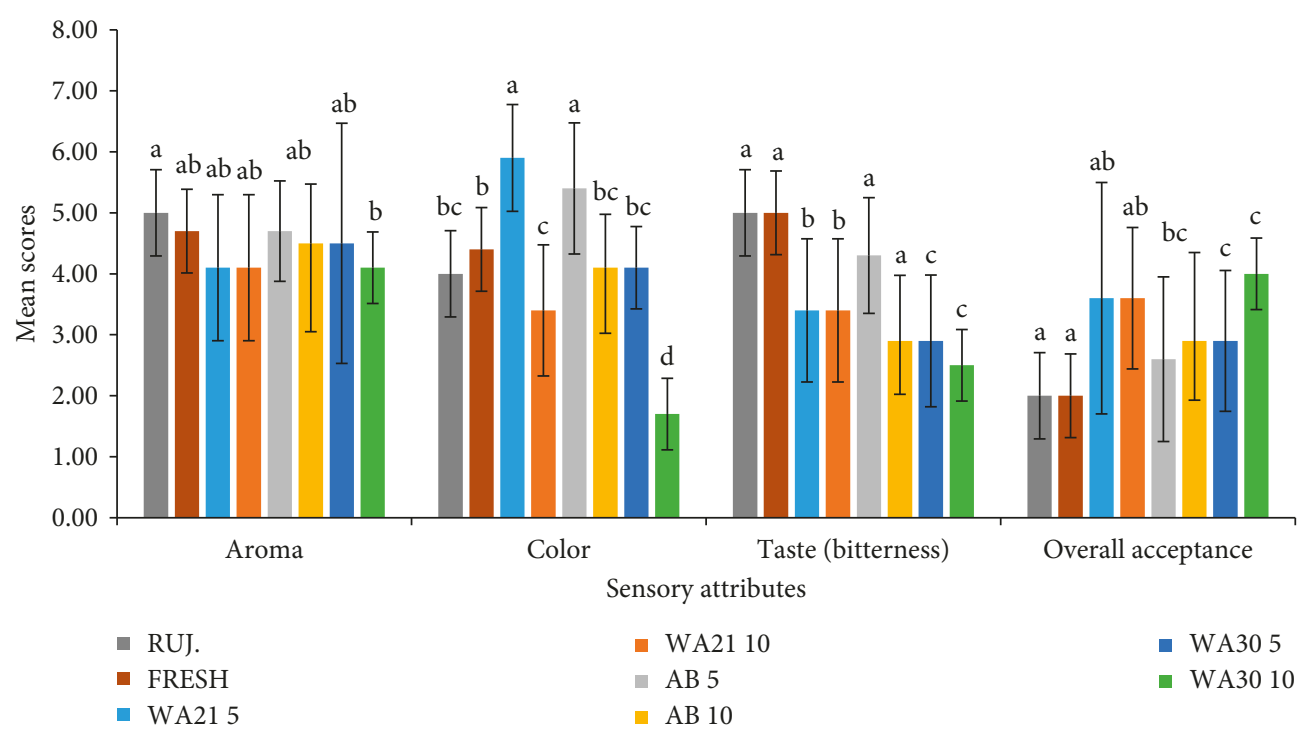

Figure 10: Mean scores of four tested sensory attributes (odor, color, taste, and overall acceptance) of C. papaya leaf extracts. a-d: different alphabets indicate a significant difference $(p<0.05)$.

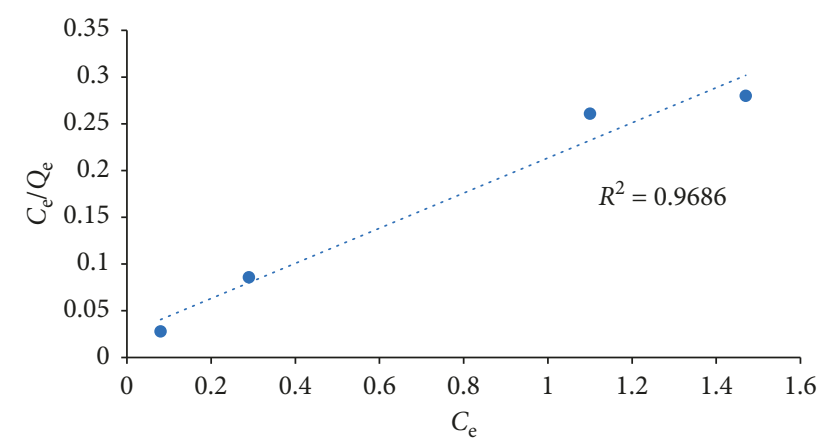

FIGURE 11: Isothermal adsorption of the saponin compound by Resion Diaon WA30 with 10\% (w/v).

dose of $10 \%(\mathrm{w} / \mathrm{v})$ had the highest percentage of saponin removal after the adsorption process. Through adsorption studies using the Langmuir isotherm model, the results
TABLE 5: Kinetic study on adsorption activity of the saponin compound by using resin Diaon WA30 10\% (w/v).

\begin{tabular}{lcccc}
\hline$C_{0}(\mathrm{mg} / \mathrm{L})$ & 17.50 & 13.85 & 8.98 & 7.98 \\
$R_{\mathrm{L}}$ & 0.167 & 0.243 & 0.312 & 0.398 \\
\hline
\end{tabular}

showed adsorption using Resin Diaon WA30 was encouraging with $R_{\mathrm{L}}$ values ranging from 0 to $1\left(0<R_{\mathrm{L}}<1\right)(0.167$ to 0.398$)$. This shows that Resin Diaon WA30 is effective in adsorption of the saponin compound.

\section{Data Availability}

The data used to support the findings of this study are available from the corresponding author upon request.

\section{Conflicts of Interest}

The authors declare that they have no conflicts of interest. 


\section{Acknowledgments}

The authors would like to thank the Ministry of Science, Technology and Innovation (MOSTI) and Ministry of Higher Education (MOE) Malaysia for providing financial support to this project (06-01-02-SF1271, FRGS/2/2013/TK04/UKM/ 03/1, and GGPM-2013-078).

\section{References}

[1] D. J. Du Puy and I. R. H. Telford, "Chapter 30: Caricaceae. Dlm. George, A. S. (pnyt.)," Flora of Australia Volume 50: Oceanic Islands 2, pp. 163-164, Australian Government Publishing Service, Canberra, Australia, 1993.

[2] V. M. Badillo, "Carica L. vs. Vasconcella St. Hil. (Caricaceae)," Con la Rehabilitación de este Ultimo, vol. 10, pp. 74-79, 2000.

[3] F. A. Bamisaye, E. O. Ajani, and J. B. Minari, "Prospects of ethnobotanical uses of pawpaw (Carica papaya)," Journal of Medicinal Plant Studies, vol. 1, no. 4, pp. 171-177, 2013.

[4] K. Sathasivam, S. Ramanathan, S. M. Mansor, M. R. Haris, and W. H. Wernsdorfer, "Thrombocyte counts in mice after the administration of papaya leaf suspension," Wiener Klinische Wochenschrift, vol. 121, no. S3, pp. 19-22, 2009.

[5] F. Yunita, E. Hanani, and J. Kristiano, "The effect of Carica papaya L. Leaves extract capsules on platelets count and haematocrit level in dengue fever patient," International Journal of Medicinal Aromatic Plants, vol. 2, pp. 573-578, 2012.

[6] N. Ahmad, H. Fazal, M. Ayaz, B. H. Abbasi, I. Mohammad, and L. Fazal, "Dengue fever treatment with Carica papaya leaves extract," Asian Pacific Journal of Tropical Biomedicine, vol. 1, no. 4, pp. 330-333, 2011.

[7] J. Duke, “Carica papaya L. (Caricaceae)," May 2016, http:// sun.ars-grin.gov:8080/npgspub/xsql/duke/plantdisp.xsql? taxon=209.

[8] P. B. Ayoola and A. Adeyeye, "Phytochemical and nutrient evaluation of Carica papaya (pawpaw) leaves," International Journal of Recent Research and Applied Studies, vol. 5, no. 3, pp. 325-328, 2010.

[9] T. H. Grenby, "Intense sweeteners for the food industry: an overview," Trends in Food Science and Technology, vol. 2, pp. 2-6, 1991.

[10] I. Kitagawa, "Licorie root: a natural sweetener and an important ingredient in Chinese medicine," Pure and Applied Chemistry, vol. 74, no. 7, pp. 1189-1198, 2002.

[11] A. D. Muir, D. Paton, K. Ballantyne, and A. A. Aubin, Process for Recovery and Purification of Saponins and Sapogenins from Quinoa (Chenopodium quinoa), United States Patent and Trademark, Alexandria, VA, United States, 2002.

[12] E. Aldin, H. A. Reitmeier, and P. Murphy, "Bitterness of soy extracts containing isoflavones and saponins," Journal of Food Science, vol. 71, no. 3, pp. S211-S215, 2006.

[13] K. R. Price, I. T. Johnson, and G. R. Fenwick, "The chemistry and biological significance of saponins in foods and feeding stuffs," CRC Critical Reviews in Food Science and Nutrition, vol. 26, pp. 27-135, 1987.

[14] L. Heng, J. Vincken, G. A. van Koningsveld et al., "Bitterness of saponins and their content in dry peas," Journal of the Science of Food and Agriculture, vol. 86, no. 8, pp. 1225-1231, 2006.

[15] S. G. Sparg, M. E. Light, and J. van Staden, "Biological activities and distribution of plant saponins," Journal of Ethnopharmacology, vol. 94, no. 2-3, pp. 219-243, 2004.
[16] C. Y. Cheok, H. A. K. Salman, and R. Sulaiman, "Extraction and quantification of saponins: a review," Food Research International, vol. 59, pp. 16-40, 2014.

[17] J. Azmir, I. S. M. Zaidul, M. M. Rahman et al., "Techniques for extraction of bioactive compounds from plant materials: a review," Journal of Food Engineering, vol. 117, no. 4, pp. 426-436, 2013.

[18] E. C. M. Coxworth and R. E. Salmon, "Kochia seed as a component of the diet of turkey poults: effects of different methods of saponin removal or activation," Canadian Journal of Animal Science, vol. 52, no. 4, pp. 721-729, 1972.

[19] Q. V. Vuong, S. Hirun, T. L. K. Chuen et al., "Antioxidant and anticancer capacity of saponin-enriched Carica papaya leaf extracts," International Journal of Food Science and Technology, vol. 50, no. 1, pp. 169-177, 2015.

[20] M. D. Vetal, V. G. Lade, and V. K. Rathod, "Extraction of ursolic acid from Ocimum sannctum by ultrasound: process intensification and kinetic studies," Chemical Engineering and Processing: Process Intensification, vol. 69, pp. 24-30, 2013.

[21] S. M. Shafaei, A. A. Masoumi, and H. Roshan, "Analysis of water absorption of bean and chickpea during soaking using Peleg model," Journal of the Saudi Society of Agricultural Sciences, vol. 15, no. 2, pp. 135-144, 2014.

[22] F. N. Mohd Fazil, N. S. Mohd Azzimia, B. Hisham Yahaya, N. Atikah Kamalaldin, and S. I. Zubairi, "Kinetics extraction modelling and antiproliferative activity of Clinacanthus nutans water extract," The Scientific World Journal, vol. 2016, Article ID 7370536, 7 pages, 2016.

[23] O. Corzo, N. Brancho, and J. Rodriguez, "Comparison of Peleg and Azura et al. models in the modelling mass transfer during pile salting of goat sheets," LWT-Food Science and Technology, vol. 4, no. 2, pp. 448-452, 2012.

[24] Y. S. Yien, O. Hassan, and S. I. Zubairi, "Deodorizing mechanism of $\beta$-cyclodextrin-organic acids inclusion against strong odor of Morinda citrifolia (Mengkudu) Juice," Jurnal Teknologi, vol. 79, no. 10, pp. 67-75, 2016.

[25] H. Hashim, S. I. Zubairi, W. A. M. Mustapha, and M. Y. Maskat, "Characterizing the deacidification adsorption model of organic acids and phenolic compounds of noni extract using weak base ion exchanger," Journal of Chemistry, vol. 2018, Article ID 6376929, 10 pages, 2018.

[26] H. Haslaniza, W. A. Wan Yaacob, Z. Saiful Irwan, and M. Y. Maskat, "Potential of Amberlite IRA-67 resin for deacidification of organic acids in noni juice," Der Pharma Chemica, vol. 7, no. 12, pp. 62-69, 2015.

[27] J. Kluczka, T. Korowais, M. Zolotajkin, and J. Adamek, "Boron removal from water and wastewater using new polystyrene-based resin grafted with glycidol," Water Resources and Industry, vol. 11, pp. 46-57, 2015.

[28] Q. V. Vuong, S. Hirun, P. D. Roach, M. C. Bowyer, P. A. Phillips, and C. J. Scarlett, "Effect of extraction condition on total phenolic compounds and antioxidant activities of Carica papaya leaf aqueous extract," Journal of Herbal Medicine, vol. 3, no. 3, pp. 104-111, 2013.

[29] H. O. A. Ahmed and C. Wang, "Determination of tea saponin in Camellia seed oil with UV and HPLC analysis," World Journal of Engineering and Technology, vol. 3, no. 4, pp. 30-37.

[30] M. J. Ahn and J. Kim, "Identification and quantification of steroidal saponins in Polyganatum species by HPLC/ESI/MS," Archives of Pharmacal Research, vol. 28, no. 5, pp. 592-597, 2005.

[31] A. J. Empungan, "Penjerapan sebatian saponin dalam ekstrak daun Carica papaya menggunakan resin penukar ion berbes lemah," Tesis Ijazah Sarjana Muda, Program Sains Makanan, 
Pusat Pengajian Sains Kimia dan Teknologi Makanan, Fakulti Sains dan Teknologi, Universiti Kebangsaan Malaysia, Bangi, Malaysia, 2015.

[32] J. Jiang, Z. Wu, W. Liu, Y. Gao, S. Guo, and S. Kang, "Separation of soybean saponins from soybean meal by a technology of foam fractionation and resin adsorption," Preparative Biochemistry and Biotechnology, vol. 46, no. 4, pp. 346-353, 2015.

[33] O. L. Charles and S. A. Odomelam, "Studies on adsorbent dosage, particle sizes and $\mathrm{Ph}$ constraints on biosorption of $\mathrm{Pb}$ (II) and Cd(II) Ions from aqueous solution using modified Crasstrotrea gasar (Bivalve) biomass," International Archive of Applied Sciences and Technology, vol. 1, pp. 62-68, 2010.

[34] P. Koujalagi, R. Kulkarni, S. Divekar, and R. Nugaraie, "Kinetics, thermodynamic and adsorption studies on removal of chromium (VI) using Tulsion A-27(MP) resin," Desalination and Water Treatment, vol. 51, no. 16-18, pp. 3273-3283, 2013.

[35] A. M. Aljeboree, A. N. Alshirifi, and A. F. Alkaim, "Kinetics and equilibrium study for the adsorption of textile dyes on coconut shell activated carbon," Arabian Journal of Chemistry, vol. 10, no. S2, pp. S3381-S3393, 2014.

[36] C. S. Gulipalli, B. Prasad, and K. L. Wasewar, "Batch study, equilibrium and kinetics of adsorption of selenium using rice husk ash (RHA)," Journal of Engineering Science and Technology, vol. 6, no. 5, pp. 586-605, 2011.

[37] F. M. Clydesdale, "Color as a factor in food choice," Critical Reviews in Food Science and Nutrition, vol. 33, no. 1, pp. 83-101, 1993

[38] C. Spence, "On the psychological impact of food colour," Flavour, vol. 4, no. 1, pp. 1-9, 2015.

[39] J. N. Putro, A. Kurniawan, S. Ismadji, and Y. H. Ju, "Nanocelluluse based biosorbents for wastewater treatment: Study of isotherm kinetic, thermodynamic and reusability," Environmental Nanotechnology, Monitoring and Management, vol. 8, pp. 134-149, 2017.

[40] A. Babarinde and G. O. Onyiaocha, "Equilibrium sorption of divalent metal ions onto groundnut (Arachis hypogaea) shell: kinetics, isotherm and thermodynamics," Chemistry International, vol. 2, no. 3, 2016. 


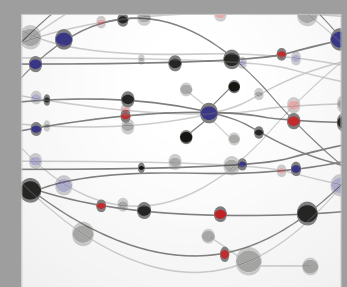

The Scientific World Journal
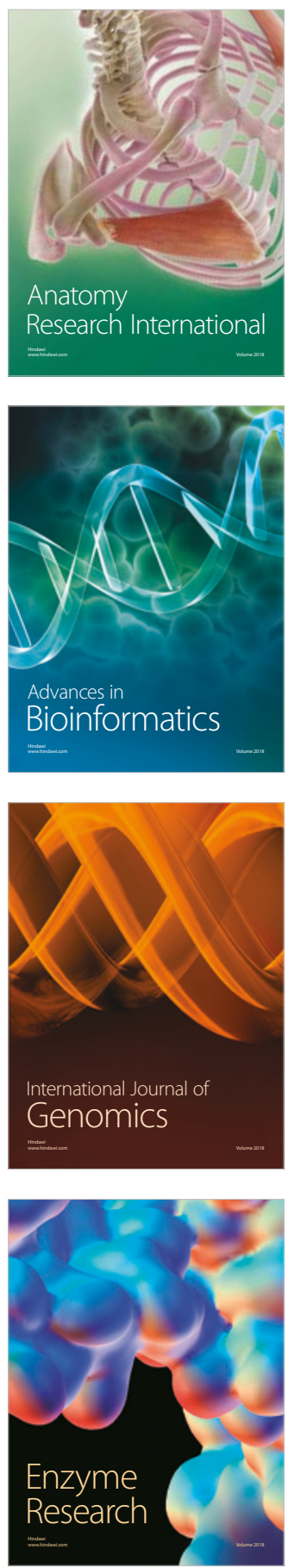
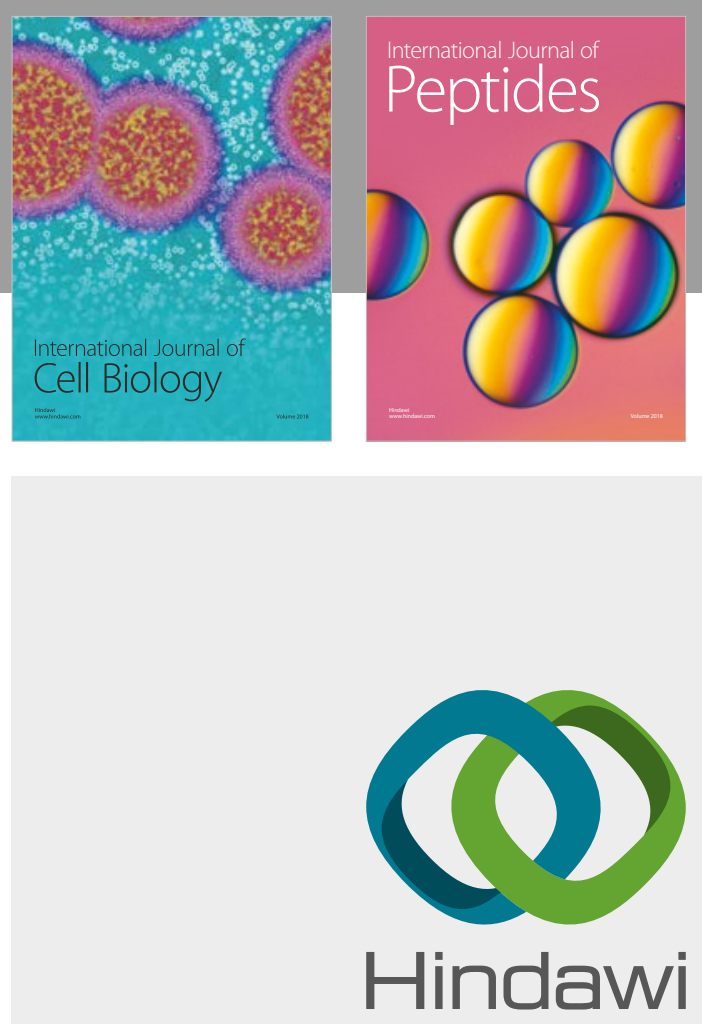

Submit your manuscripts at

www.hindawi.com
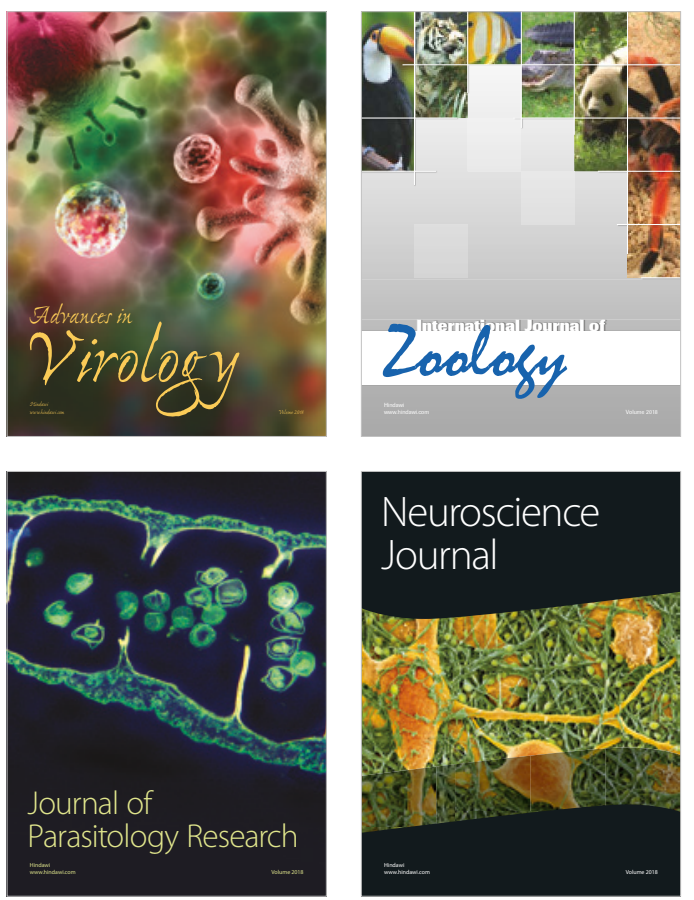
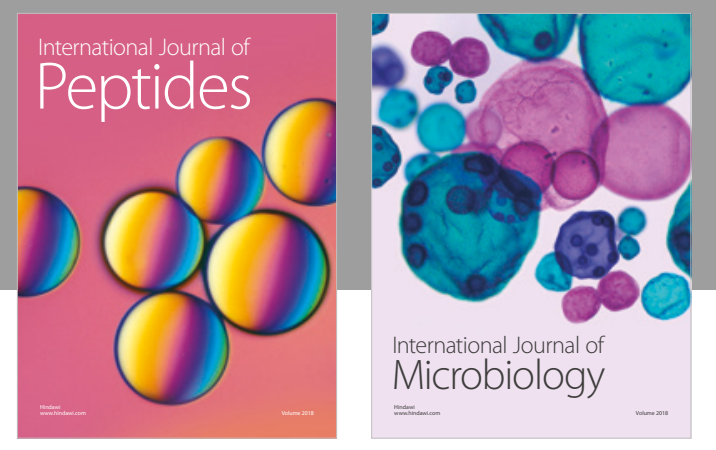

nternational Journal of Microbiology
Journal of
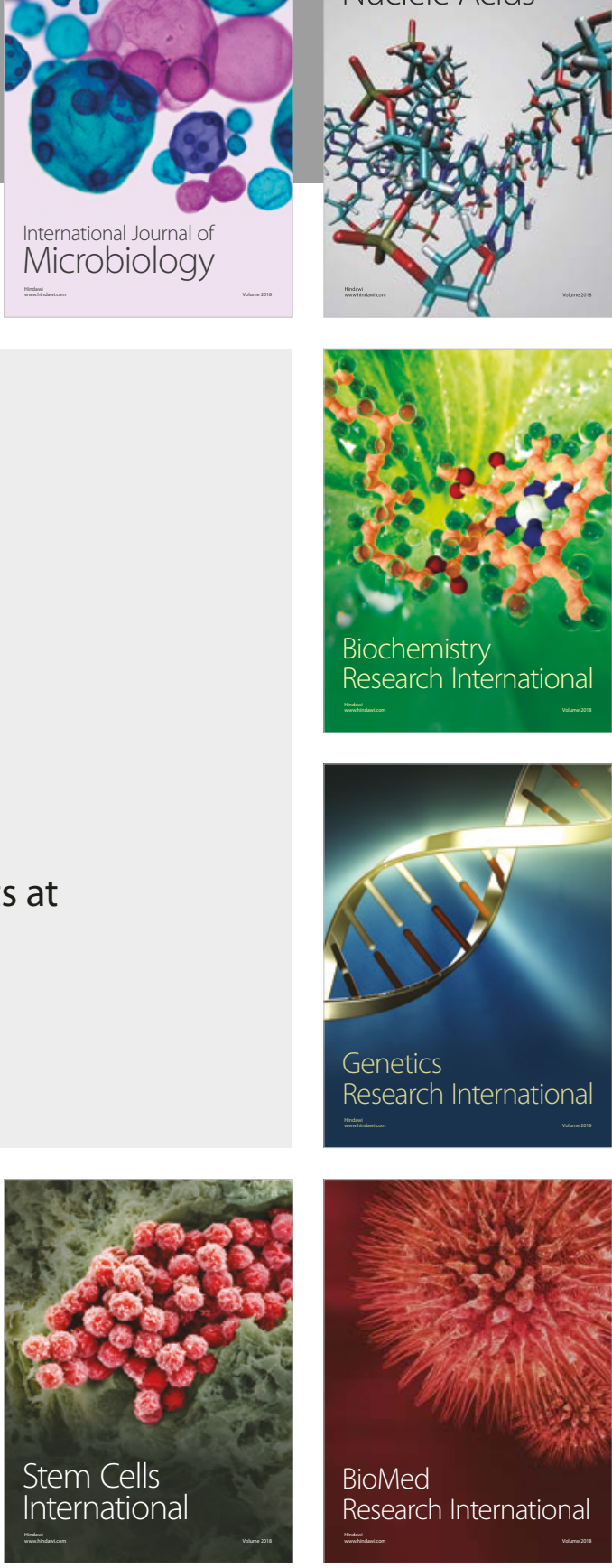
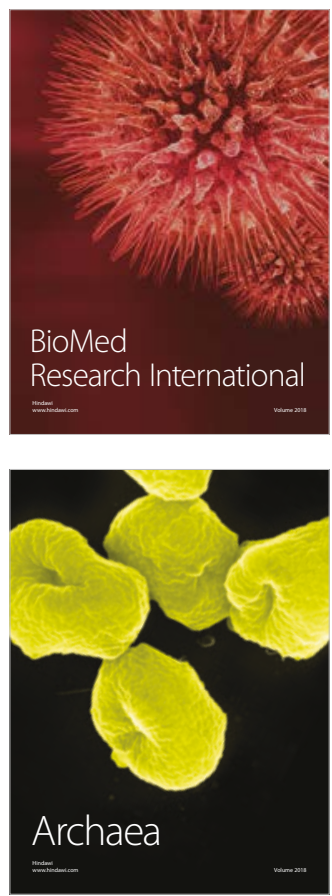